\title{
Diagnosis of unsafe chronic suppurative otitis media using computed tomography through predictive value assessments
}

\author{
Shukla N. ${ }^{1}$, Giri R.K. ${ }^{2}$, Sharma V. ${ }^{3}$ \\ ${ }^{1}$ Dr. Naveen Shukla, Assistant Professor, ${ }^{2}$ Dr. Rakesh Kumar Giri, Senior Resident, Both authors are affiliated with \\ Department of Otorhinolaryngology at Shridev Suman Subharti Medical College, Dehradun, ${ }^{3}$ Dr. Varuni Sharma, \\ Assistant Professor, Department of Obstetrics and Gynaecology at Shridev Suman Subharti Medical College, Dehradun, \\ Uttarakhand, India.
}

Correspondence Author: Dr. Rakesh Kumar Giri, Senior Resident, Department of Otorhinolaryngology at Shridev Suman Subharti Medical College, Dehradun E-mail: rakeshgiri57@gmail.com

\begin{abstract}
Background: Chronic Suppurative Otitis Media (CSOM) is a significant cause of preventable hearing loss. Global emergence of resistant strains is of great concern. The aim of the present study was to assess the accuracy and predictive value of computed tomography in diagnosis of unsafe chronic suppurative otitis media. Methods: Aprospective, analytical study was conducted among 90 patients with complaint of unsafe chronic suppurative otitis media which were randomly selected from outpatient Department of Otorhinolaryngology at Subharti Medical College, Dehradun, Uttarakhand. The patients comprised of both males as well as females and also of different age groups. Results: Out of 90 patients, 61(67.22\%) were males followed by 29 (32.22\%) females. The minimum age of patient in the study was of 8 years and the maximum age of patient in study of 50 years. Maximum number of patients belonged to the age group of $11-20(50 \%)$. The mean age in this study was 23 years. Among study subjects, $32(35.55 \%)$ cases had conductive hearing loss, $11(12.22 \%)$ cases had sensorineural type, $40(44.44 \%)$ had mixed type and $7(7.77 \%)$ had no response. In this study, sensitivity, specificity, positive predictive value, negative predictive value was calculated of computed tomography findings as compared to preoperative findings. The sensitivity of HRCT for mastoid was $100 \%$, visualization malleus was $94.11 \%$, incus was also $62.31 \%$, stapes was $47.22 \%$ and facial $\mathrm{N}$ dehiscent and intact was $44.82 \%$. Similarly, the specificity of CT scan for mastoid was $83.33 \%$, malleus was $92.85 \%$, incus was $61.90 \%$, stapes erosion was $37.03 \%$ and facial $\mathrm{N}$ dehiscent was $96.72 \%$. Conclusion: The present study was concluded that computed tomography can accurately image the findings in unsafe chronic suppurative otitis media and represents a major advance in the diagnostic imaging of this disease.
\end{abstract}

Keywords: Chronic suppurative otitis media, Predictive value, Computed tomography

\section{Introduction}

Chronic suppurative otitis media is typically a persistent disease, insidious in onset, capable of causing severe destructions and irreversible sequelae. It clinically manifests as deafness and chronic intermittent aural discharge [1].

The widespread prevalence of chronic suppurative otitis media in third world countries can be attributed to the socioeconomic factors such as poor living conditions, overcrowding, poor hygiene and nutrition [2]. Chronic suppurative otitis media has been classified into two main group's Tubotympanic and atticoantral disease.

Manuscript received: $3^{\text {rd }}$ April 2019

Reviewed: $14^{\text {th }}$ April 2019

Author Corrected: $19^{\text {th }}$ April 2019

Accepted for Publication: $26^{\text {th }}$ April 2019
Atticoantral is considered a dangerous form of the disease in lieu of the risks of intracranial complications. The typical feature of atticoantral disease is the prevalence of cholesteatoma [3]. Aural cholesteatoma, a middle ear disease entity described first by Cruveilhier in 1829 as a pearly tumor is yet in many respects ill understood. This dangerous disease process has so much to reveal even after more than a century of its discovery [4]. The standard management of chronic suppurative otitis media is surgical. The management of chronic suppurative otitis media has witnessed a profound change over the last century; from early attempts at surgical exposure of the middle ear to the present day techniques of Tympanoplasty in persistent but inactive disease and the canal up and canal down 


\section{Original Research Article}

procedure in case of cholesteatomas [5]. Morgagni (1982-1771) was the first to recognize that suppuration in the brain was secondary to ear infection and he further emphasized the potentially serious nature of ear infection. Different view regarding this subject has been put forward by various authors.

When the German physiologist Johannes Mueller covered the term cholesteatoma in 1838 he was identifying "a layered pearly tumor of fat, which was distinguished from other fat tumors by the biliary fat (cholesterin) that is interspersed among the sheets of "polyhedral cells" [6].

Although Mueller coined the term, it was the French pathologist Cruveilhier who first described the pathologic features of this disease. The aim of this study is to assess the predictive value of computed tomography in the diagnosis of unsafe chronic suppurative otitis media.

\section{Materials and Methods}

A prospective, analytical study was conducted among 90 patients with unsafe chronic suppurative otitis media which were randomly selected from outpatient Department of Otorhinolaryngology at Subharti Medical College, Dehradun, Uttarakhand.
The patients comprised of both males as well as females and also of different age groups. A detailed history with regard to otorrhoea, deafness, tinnitus, otalgia and vertigo was taken and recorded in a systemic manner. A complete general physical examination was carried out followed by otorhinolaryngological examination which included otoscopic examination and examination under microscope. Unsafe CSOM involves cholesteatoma. Cholesteatoma is a non-malignant but destructive lesion of the skull base [7].

Assessment of hearing was done by tuning fork tests and pure tone audiometry. Routine haematological and urine investigations were carried out in each case along with X-ray chest PA view and ECG wherever indicated. Patients with malignancy of the ear, patients unfit for surgery or anesthesia and patients who were pregnant were excluded from the study.

Written informed consent were taken from study subjects and approval for the study was obtained from Institutional Research and Ethical Committee. Associated symptomatology suggestive of impending or already established complications of unsafe chronic suppurative otitis media was enquired into and noted. All cases were investigated and subsequently operated with an aim to correlate the radiological and operative findings.

\section{Results}

A total number of 90 cases of unsafe type of chronic suppurative otitis media were selected for present study.

Table-1: Demographic distribution of patients

\begin{tabular}{|c|c|c|}
\hline Age (yrs) & Number of patients & Percentage \\
\hline $0-10$ & 4 & $4.44 \%$ \\
\hline $11-20$ & 45 & $50 \%$ \\
\hline $21-30$ & 30 & 33.33 \\
\hline $31-40$ & 2 & $2.22 \%$ \\
\hline $41-50$ & 9 & $10 \%$ \\
\hline Sex & Number of patients & Percentage \\
\hline Male & 61 & $67.77 \%$ \\
\hline Female & 29 & $32.22 \%$ \\
\hline Type of hearing loss & Number of patients & Percentage \\
\hline Conductive & 32 & $35.55 \%$ \\
\hline Sensorineural & 11 & $12.22 \%$ \\
\hline Mixed & 40 & $44.44 \%$ \\
\hline No response & 7 & $7.77 \%$ \\
\hline
\end{tabular}

The above table illustrates that the patients belonged to age groups varying from first decade to fifth decade. The youngest patient was of 8years and the eldest of 50 years. Maximum number of patients belonged to the age group of 11$20(50 \%)$. The mean age in this study was 23 years. There was marked male preponderance in this study. 


\section{Original Research Article}

Out of a total number of 90 patients, total of males were $61(67.77 \%)$ and number of females were 29 (32.22\%). Out of total number of 90 patients, $32(35.55 \%)$ cases had conductive hearing loss, 11(12.22\%) cases had sensorineural type, $40(44.44 \%)$ had mixed type and $7(7.77 \%)$ had no response.

Table-2: Sensitivity, Specificity, Positive predictive value and Negative predictive value of findings in computed tomography among study subjects.

\begin{tabular}{|c|c|c|c|c|c|c|}
\hline Variable Name & $\begin{array}{c}\text { Per op disease } \\
\text { present }\end{array}$ & $\begin{array}{c}\text { Per op disease } \\
\text { absent }\end{array}$ & Sensitivity & Specificity & PPV & NPV \\
\hline CT : disease present & 80 & 0 & \multirow{2}{*}{$91.95 \%$} & \multirow{2}{*}{$100 \%$} & \multirow{2}{*}{$100 \%$} & \multirow{2}{*}{$30 \%$} \\
\hline CT: disease absent & 7 & 3 & & & & \\
\hline CT : sclerosed mastoid & 72 & 3 & \multirow{2}{*}{$100 \%$} & \multirow{2}{*}{$83.33 \%$} & \multirow{2}{*}{$96 \%$} & \multirow{2}{*}{$100 \%$} \\
\hline CT: cellular mastoid & 0 & 15 & & & & \\
\hline CT : disease present & 78 & 2 & \multirow{2}{*}{$97.5 \%$} & \multirow{2}{*}{$80 \%$} & \multirow{2}{*}{$97.5 \%$} & \multirow{2}{*}{$80 \%$} \\
\hline CT: disease absent & 2 & 8 & & & & \\
\hline $\begin{array}{l}\text { CT : Tegmen tympani } \\
\text { eroded }\end{array}$ & 17 & 11 & \multirow{2}{*}{$60.71 \%$} & \multirow{2}{*}{$82.25 \%$} & \multirow{2}{*}{$60.71 \%$} & \multirow{2}{*}{$82.25 \%$} \\
\hline $\begin{array}{l}\mathrm{CT}: \text { Tegmen tympani } \\
\text { intact }\end{array}$ & 11 & 51 & & & & \\
\hline CT : Sinus plate eroded & 6 & 3 & \multirow{2}{*}{$75 \%$} & \multirow{2}{*}{$96 \%$} & \multirow{2}{*}{$75 \%$} & \multirow{2}{*}{$97.53 \%$} \\
\hline $\mathrm{CT}:$ Sinus plate intact & 2 & 79 & & & & \\
\hline CT : Facial N. dehiscent & 13 & 2 & \multirow{2}{*}{$44.82 \%$} & \multirow{2}{*}{$96.72 \%$} & $86.66 \%$ & $78.66 \%$ \\
\hline CT : Facial N. intact & 16 & 59 & & & & \\
\hline CT : Lat SSC Fistula & 12 & 8 & \multirow{2}{*}{$85.71 \%$} & \multirow{2}{*}{$97.14 \%$} & \multirow{2}{*}{$60 \%$} & \multirow{2}{*}{$97.14 \%$} \\
\hline CT : Lat SSC Intact & 2 & 68 & & & & \\
\hline CT : Malleus eroded & 32 & 4 & \multirow{2}{*}{$94.11 \%$} & \multirow{2}{*}{$92.85 \%$} & \multirow{2}{*}{$88.88 \%$} & \multirow{2}{*}{$96.29 \%$} \\
\hline CT : Malleus Intact & 2 & 52 & & & & \\
\hline CT : Incus eroded & 43 & 8 & \multirow{2}{*}{$62.31 \%$} & \multirow{2}{*}{$61.90 \%$} & \multirow{2}{*}{$84.31 \%$} & \multirow{2}{*}{$33.33 \%$} \\
\hline CT : Incus Intact & 26 & 13 & & & & \\
\hline $\begin{array}{l}\mathrm{CT}: \text { Stapes } \\
\text { suprastructure eroded }\end{array}$ & 17 & 34 & & & & \\
\hline $\begin{array}{l}\mathrm{CT}: \text { Stapes } \\
\text { suprastructure Intact }\end{array}$ & 19 & 20 & $4 / .22 \%$ & $31.03 \%$ & $33.35 \%$ & $51.28 \%$ \\
\hline $\begin{array}{l}\text { CT : Disease outside } \\
\text { middle ear cleft present }\end{array}$ & 16 & 0 & $04110 \%$ & $100 \%$ & $100 \%$ & $08610 /$ \\
\hline $\begin{array}{l}\mathrm{CT}: \text { Disease outside } \\
\text { middle ear cleft Absent }\end{array}$ & 1 & 73 & 94.1170 & 10070 & 10070 & 90.0170 \\
\hline
\end{tabular}

In each above mentioned areas sensitivity, specificity, positive predictive value, negative predictive value was calculated of computed tomography findings as compared to preoperative findings. In identifying soft tissue mass in a case of unsafe chronic suppurative otitis media, computed tomography was found to be extremely effective in those without the mass, but not so much in those with the mass. On the basis of statistical analysis, there was good radio-surgical correlation between CT and operative findings. It's accuracy as a diagnostic test in this regard was thus acceptable.

In a case of unsafe chronic suppurative otitis media, computed tomography was found to be extremely effective in identifying those with sclerosis of mastoid but less effective in those with cellular mastoid. In our study, computed tomography proved to be helpful in correctly picking out the extent of the disease. Its role in spotting areas free from the disease was found to be less satisfactory. As is evident from the table above, our study demonstrated that computed tomography cannot be used as a diagnostic method for detecting erosion of the Tegmen tympani in unsafe chronic suppurative otitis media. In our study, we demonstrated that, in pinpointing patients with sinus plate erosion in unsafe chronic suppurative otitis media, computed tomography was highly effective. However, it's utility in spotting out those with a normal sinus plate was limited. In identifying facial nerve dehiscence, computed tomography was established as a poor test in our study. However it's importance in singling out those with an intact nerve was significant. 


\section{Original Research Article}

In our series of patients with unsafe chronic suppurative otitis media, the status of using computed tomography as a diagnostic investigation for lateral semicircular canal integrity of fistulization was shown to be below acceptable standards. In recognizing malleus erosion or intactness, computed tomography in our study was demonstrated to be within satisfactory norms. On behalf of the statistical analysis Kappa (K) value shows thatradiosurgical agreement was excellent for the malleus. In singling out incus erosion, computed tomography was found to be a poor investigation, as well as in patients with an intact incus. For stapes erosion demonstration, computed tomography shown to have no role at all, in view of its inability in correctly picking out those with or without erosion. Computed tomography proved to be an excellent investigation in our study in spotting patients without disease outside middle ear cleft with no false positives.

Its efficacy in identifying those with disease outside middle ear cleft was however borderline. For this purpose cases of unsafe chronic suppurative otitis media were evaluated clinically and through computerized tomography in order to get an idea about the middle ear and mastoid status. Subsequently surgery was undertaken in the above selected cases and an attempt was made to correlate computerized tomography with per operative findings.

\section{Discussion}

The present study was conducted to assess the predictive values of computed tomography in diagnosis of unsafe chronic suppurative otitis media and correlating it with preoperative findings so that attempts can be made to restore or conserve hearing and promote healing, after the excision of disease from the middle ear and mastoid.

The diagnosis of unsafe chronic suppurative otitis media has been relied in the past mainly on history, clinical examination, otoscopy, pure tone audiometry, and plain $\mathrm{x}$-rays. There is no doubt that clinical examination has been, by far, the principle means of diagnosis and radiology has been the least important. At present, the type of surgery available, is very varied, elaborate, lengthy and often staged. It is of help to the surgeon and to the patient to know as much as possible what is involved, so as to turn as 'exploration' in to a planned procedure. It is in view of this, unsafe chronic suppurative otitis media should be reassessed. A total of 90 cases were selected and each of the selected cases of unsafe chronic suppurative otitis media were subjected to computed tomography of temporal bone. In every patient both axial and coronal sections were taken, taking high resolution section of 1-2 mm thickness.

These cases were undertaken for surgical exploration and finally an attempt was made to correlate the preoperative findings with preoperative computed tomography findings [8]. In this study, incus was most commonly affected ossicle followed by malleus and stapes. The sensitivity of HRCT for mastoid was $100 \%$, visualization malleus was $94.11 \%$, incus was also $62.31 \%$, stapes was $47.22 \%$ and facial $\mathrm{N}$ dehiscent and intact was $44.82 \%$. Similarly, the specificity of CT scan for mastoid was $83.33 \%$, malleus was $92.85 \%$, incus was $61.90 \%$, stapes erosion was $37.03 \%$ and facial $\mathrm{N}$ dehiscent was $96.72 \%$.
The study findings are consistent similar with the findings of Chee et al. and in context to study by Tatlipinar et al. who observed sensitivity of $62.8 \%$ and specificity of $85.7 \%$ for the same $[9,10]$.

The findings of the study in which computed tomography had a sensitivity of $60.71 \%$ and specificity of $82.25 \%$ with regards to detection of erosion of tegmen tympani plate, which is comparable to study [11].

In past studies $[12,13,14,15]$, computed tomography was found up to $100 \%$ sensitive in detecting a soft tissue mass preoperative. Our data showed a slightly lower sensitivity of $91.95 \%$. This discrepancy could be because of greater sample size in our study. However the specificity and Positive predictive value in this regard were both $100 \%$. However, we could not distinguish cholesteatoma from other soft tissue disease, and this again was the experience of most authors. The differential diagnosis of soft tissue mass is often quite difficult with computed tomography. We have been unsuccessful most of the times in differentiating pathologic processes on the basis of computed tomography number. Acquired cholesteatoma, granulation tissue (in the absence of haemorrhage) and middle ear effusion all share computed tomography numbers ranging from 40 to 65 . We therefore must rely on secondary findings to help in differential diagnosis.

Thus after clinical examination, otoscopy and diagnosis of cholesteatoma, computed tomography can determine its extent by revealing the combination of a soft tissue mass and bone erosion with $80 \%$ specificity. In studies on efficiency of computed tomography in defining the extent of disease preoperatively, O'Donoghue et al and MacAfee et al independently found computed tomography to be highly accurate $[16,17]$. 


\section{Original Research Article}

O'Reilly et al, in his study, corroborated the above studies with a $100 \%$ sensitivity of computed tomography in defining the extent of disease. In our study, the sensitivity and Positive Predictive Value were both $97.5 \%$ which is in agreement with the aforementioned studies [18].

O' Donoghue et al, reported a sensitivity of $50 \%$ in identifying Tegmen tympani erosion but did not report his false positives [16]. O' Reilly et al showed sensitivity of $46 \%$ and specifity of $84 \%$ [18]. Macfee et al, showed a sensitivity of $50 \%$ and a positive predictive value of $100 \%$ for detecting tegmen erosion [19]. Pandey et al, reported a sensitivity of $100 \%$ but a PPV of $33.33 \%$ in this regard [20].

In our study, the sensitivity and positive predictive value were both $60.71 \%$. These non-correlating values can be explained partly by the very small number of patients with tegmen erosion in these studies, and also on the fact stated [21]. He commented that it is not possible to demonstrate reliably a dehiscence in the tegmen on axial scan alone but even using coronal cuts they found that the effect of partial volume averaging with adjacent soft tissue could give a false impression of tegmen tympani erosion. In detecting sinus plate erosion on computed tomography our study showed sensitivity of $75 \%$, specificity of $96 \%$, positive Predictive Value of $75 \%$ and negative Predictive Value of $97.53 \%$. Hence in our study, we demonstrated that, in pinpointing patients with sinus plate erosion in unsafe chronic suppurative otitis media, computed tomography was highly effective. However, it's utility in spotting out those with a normal sinus plate was limited. In previous studies, the sensitivity of computed tomography in detecting facial canal dehiscence varied widely with values of $0 \%, 25 \%, 44 \%$, and $100 \%$ $[18,22,23]$.

The specificity has been reported only by O'Reilly as $85 \%$. In our study, the sensitivity was $44.82 \%$ and specificity was $96.72 \%$, which was comparable to the O.' Reilly study [18]. These non-compliant results can be explained on the fact that the visualization on thin bony structures like facial nerve canal may be misleading due to errors in scanning eroded portions due to the fact that the computer averages their density with adjacent soft tissue and air.

Limitations: The present study have some limitations. The limited sample size of the study could have affected the interpretation of the obtained result. Clearly, more studies involving a larger sample size are warranted in future.

\section{Conclusion}

In conclusion, the present study pointed that high resolution computed tomography scanning is a modality which can accurately image the pathological anatomy in unsafe chronic suppurative otitis media and represents a major advance in the diagnostic imaging of this disease. Its use by otologists is encouraged, especially in patients who have or are suspected of having complex problems and in whom the maximum information is desirable for preoperative assessment.

Acknowledgement: This research was supported by Research Committee at Shridev Suman Subharti Medical College, Dehradun. We thank our colleagues from Department of Otorhinolaryngology and Department of Obstetrics and Gynaecology at Shridev Suman Subharti Medical College, Dehradun who provided insight and expertise that greatly assisted the research.

\section{Funding: Nil, Conflict of interest: Nil Permission from IRB: Yes}

\section{References}

1. Shenoi PM. Management of chronic suppurative otitis media. In: Booth JB, editor. Scott Browns otolaryngology. 5. London: Butterworths; 1987. pp. 215-237.

2. WHO/CIBA Foundation workshop report, Prevention of hearing impairment from chronic otitis media.UK 19-21 Nov 1996.

3. Varshney S, Nangia A, Bist SS, Singh RK, Gupta N, Bhagat S. Ossicular chain status in chronic suppurative otitis media in adults. Indian J Otolaryngol Head Neck Surg. 2011;62(4):421-426. doi:10.1007/s12070-0100116-3

4. Agarwal NM, Popat VC, Traviad C, et al. Clinical and histopathological study of mass in ear: a study of fifty cases. Indian J Otolaryngol Head Neck Surg. 2013 Dec;65(Suppl 3):520-5. doi: 10.1007/s12070-011-04340. Epub 2012 Feb 11.

5. Mishiro Y., Sakagami M., Takahashi Y., Kitahara T., Kajikawa H., Kubo T. Tympanoplasty with and without mastoidectomy for non-cholesteatomatous chronic otitis media. Eur Arch Otorhinolaryngol. 2001. 258 13-15. doi:10.1007/PL00007516.

6. Worku M, Bekele $M$. Bacterial isolate and antibacterial resistance pattern of ear infection among 


\section{Original Research Article}

patients attending at Hawassa university referral Hospital, Hawassa, Ethiopia. Indian J Otol2014;20: 155-9.

7. Chronic suppurative otitis media - burden of illness and management options; World Health Organization, 2004.

8. Singh A, Pandey S and Gaur A. "Burden of noncommunicable diseases on two different division of Uttarakhand: Adult health indicator", International Journal of Development Research, 2018. 8, (12), 24480-24485.

9. Chee NW, Tan TY. The value of pre-operative high resolution CT scans in cholesteatoma surgery. Singapore Med J. 2001 Apr;42(4):155-9.

10. Tatlipinar, A., Tuncel, A., Öğredik, E. A., Gökçeer, T., \&Uslu, C. The role of computed tomography scanning in chronic otitis media. Eur Arch Otorhinolaryngol. 2012 Jan;269(1):33-8. doi: 10.1007/s 00405-011-1577-z.

11. Jackler RK, Dillon WP, Schindler RA. Computed tomography in suppurative ear disease: a correlation of surgical and radiographic findings. Laryngoscope. 1984 Jun;94 (6):746-52.

12. Kangsanarak J, Fooanant S, Ruckphaopunt K, et al. Extracranial and intracranial complications of suppurative otitis media. Report of 102 cases. J Laryngol Otol. 1993 Nov;107(11):999-1004.

13. Singh B, Maharaj TJ. Radical mastoidectomy: its place in otitic intracranial complications. J Laryngol Otol. 1993 Dec;107(12):1113-8.

14. Lampikoski H, Aarnisalo AA, Jero J, et al. Mastoid biofilm in chronic otitis media. OtolNeurotol. 2012 Jul;33 (5): 785-8. doi: 10.1097 / MAO. 0b013e318 259533f.

15. Gaurano JL, Joharjy IA. Middle ear cholesteatoma: characteristic CT findings in 64 patients. Ann Saudi
Med. 2004 Nov-Dec;24(6):442-7. DOI:10.5144/02564947.2004.442.

16. O'Donoghue G M, Bates G J. Anslow P. Rothera P. The predictive value of high resolution computerized tomography in chronic suppurative ear disease. Clinical otolaryngology 1983;12:89-96. https://doi.org/ 10.1111 /j.1365-2273.1987.tb00168.x

17. Mafee MF, Levin BC, Applebaum EL, et al. Cholesteatoma of the middle ear and mastoid. A comparison of CT scan and operative findings. Otolaryngol Clin North Am. 1988 May;21(2):265-93.

18. O'Reilly BJ, Chavertton Ear B, Wylie.1, Thakkar C, Butler P, Sathanathan N, Morrison GA, Kenyon GS. Value of computed tomography scanning in chronic suppurative otitis media; J of Laryngology and Otology Dec 1991;105:990-994.

19. Shaffer, K. A., Haughton, V. M., Wilson, C. R. (1980). High Resolution Computed Tomography of the Temporal Bone. Radiology, 134:409-414.

20. Pandey S, Singh A, Gaur A. Polynomial approach modeling among diabetic patients associated with age in rural hilly population of Dehradun district, Uttarakhand. Int J Res Med Sci 2018;6:1-5. DOI: 10.18203/23206012.ijrms20180615

21. Payal, G., Pranjal, K., Gul, M., Mittal, M. K., \& Rai, A. K. (2012). Computed tomography in chronic suppurative otitis media: value in surgical planning. Indian journal of otolaryngology and head and neck surgery: official publication of the Association of Otolaryngologists of India,64(3), 225-229. doi:10.1007 /s12070-011-0325-4.

22. Kvestad E, Kvaerner KJ, Mair IWS. Acute Mastoiditis: predictors for surgery. Int J. Pediatr. Otorhinolaryngol. 2000;52:149-55.

23. Freng A, Larsen PL, Nordhus T. Cholesteatoma of the temporal bone. Preoperative CT versus Peroperative findings. Scandinavian Audiology Supplement. 1988; 30:185-188.

\section{How to cite this article?}

Shukla N., Giri R.K., Sharma V. Diagnosis of unsafe chronic suppurative otitis media using computed tomography through predictive value assessments. Trop J Ophthalmol Otolaryngol.2019;4(2): 80-85.doi: 10.17511/jooo.2019.i02.03 